\title{
Impact of emerging technologies in banking and finance in Europe: A volatility spillover and contagion approach ${ }^{1}$
}

\author{
Laura Arenas* and Anna María Gil-Lafuente \\ Department of Business Administration, University of Barcelona, Barcelona, Spain
}

\begin{abstract}
The empirical evidence suggests that stock returns in the emerging technology environment exhibit high stock return volatility. The fundamental aim of the article is to investigate the dynamic, time series properties of the correlations between daily log returns and magnitude of the volatility transmissions from the emerging technologies environment to the Spanish banking sector, the Spanish market portfolio and the finance industry in the EU area. Using daily log returns for the performance variables and an equally weighted index was constructed as proxy to represent the emerging technology phenomena covering a period from the $7^{\text {th }}$ of July of 2015 to the $20^{\text {th }}$ of September of 2019. The study applies generalized autoregressive conditional heteroskedasticity GARCH followed by the diagonal BEKK approach. One key finding is that the emerging technology environment is important in capturing volatility of Spanish banking sector, the Spanish market portfolio and the finance industry in the EU area through significant volatility clustering, volatility spillover and volatility persistence. Results exhibit very large GARCH and relatively low ARCH effects indicating a long persistence of resulting shocks over volatility. Broadly, the Spanish banking sector seems to be the most exposed to volatility spillover. Nevertheless, it is the finance industry across the EU which is more affected by the volatility persistence from emerging technology shocks in terms of volatility and cross - volatility point of view. Additionally, high volatility periods provide insights about an increased integration and volatility spillover. From an investor perspective, one important implication is that adding stocks from different emerging technologies to a portfolio does not necessarily lead to risk reduction.
\end{abstract}

Keywords: Emerging Technologies; Volatility Spillovers; Volatility Persistence; GARCH; Multivariate GARCH.

\section{Introduction}

Since the crisis in 2008 , the financial industry has been exponentially reaching for innovation to increase stability, improve quality of services and to rebuild trust, suggesting that the demand of innovation is driven by the financial stability. Besides, works from a different perspective have assumed that the New Economy, or the 'information age', has affected the stability of the market valuation process, and in so, doing increased

\footnotetext{
${ }^{1}$ This study is the extension of a presentation made by authors at the International Workshop "Innovation, Complexity and Uncertainty in Economics and Business", held at Royal Academy of Economic and Financial Sciences, 14th November 2019, Barcelona, Spain.

* Corresponding author. E-mail: laura.arenas.dreger@gmail.com.
} 
volatility across stock markets $[15,46]$. This article [15] indicates that the increases generalized volatility might be due to new technologies, especially those related to the 'IT 'revolution.

In this context "emerging technologies" can be absorbed under the framework of the possibility to lead a dramatic change and impact on socio-economic systems [67] and this context is extensively connected to innovation management [28].

Additionally, since stock prices are expected to reflect expectations about future profits [59,53], it makes sense that expectations about the outcome of a technological innovation also will be reflected by the stock prices and its return volatility.

Previous empirical work has focused on studying the relationship of technological innovation and stock prices over the industry life cycle and the linkage between market value, profits and patents as proxy for innovation. Despite the recognized importance of emerging technologies phenomena in descriptive literature, there have been surprisingly few empirical studies. This investigation provides several contemporaneous extensions.

The goal of this work is to empirically analyze the dynamic, time series properties of the correlations between daily $\log$ returns and magnitude of the volatility transmissions due to emerging technology to the to the Spanish banking sector, the Spanish market portfolio and the finance industry in the EU area as the performance variables.

First, we investigate the link between changes in emerging technologies and market proxies at mean and volatility terms. The Generalized autoregressive conditional heteroskedasticity GARCH methodology is used followed by a diagonal BEKK approach.

Second, we investigate the link between the emerging technologies for to the Spanish banking sector, the Spanish market portfolio and the finance industry in the EU area.

Finally, we expect that volatility of the performance variable should be affected by emerging technology phenomena as an uncertain investment. By reason, since volatility is commonly perceived as a proxy for uncertainty [59] and innovation is a perfect example of true Knightian uncertainty [48], we interpret the relationship between the emerging technologies under the innovation context and volatility [55].

Furthermore, we suggest that our results are useful for researchers studying the emerging technology phenomena and implications for market evolution and participants and what does suggest for the current regularity framework.
From the investor's perspective, insights from the risk -return trade-off will be provided through the emerging technology -return trade-off since innovation is used as a sound proxy for risk.

Besides, the exploring feature of this work is aligned with the suggestions raised by some experts $[75,41,76]$, stating that more experiments are needed to understand the phenomena of the emerging technologies [32,70,24] and possible novel viable approaches for financial regulation.

The remainder of the article is structured as follows. Section 2 reviews the literature on the theoretical as well as the empirical association between technology and emerging technology and finance industry.

Section 3 describes the data set. Section 4 presents the empirical results and section 5 develops the conclusion and provides certain directions for future research.

\section{Literature Review}

A new wave of innovation and changes can be observed. Over the last two decades, the financial industry and particularly the banking sector, have been significantly affected by rapid and intense progress in information and communication technology (ICT) $[63,64,14]$ or in other words, highly exposed to technological innovation.

Technological change is viewed as endogenous and persistence by endogenous growth models in $[65,50]$. However, in most orthodox macroeconomic models, technological change is introduced as an exogenous stochastic shock [17]. In order to provide a notion, as quoted by Freeman and colleagues [36] growth on technical innovation resembles better to a series of explosions rather than a gentle and incessant transformation.

Recent literature is focusing on the impact of the technological change and innovation on stock return volatility in order to better understand the IT Revolution or New Economy phenomena.

The rational expectation hypothesis states that the current price of a stock is equal to the rational expectations as identically to optimal forecast (the best guess of the future) using all available information [58]. Since stock prices are expected to reflect expectations about (discounted) future profits, it makes sense that expectations about the outcome of a technological innovation to also be reflected by the stock prices $[59,53]$.

Widely used under a similar approach by the literature to investigate the role of technological change and stock prices and returns, is the efficient market hypothesis, which assumes that the price traded in the market 
reflects all available information stated by Fama [35,52] and hence, the real firm's innovation potential. The efficient market hypothesis is associated extensively with the idea of a "random walk." Financial markets use often random walk to model fat tail distributions like those in the high frequency data. In the present context, heavy tails are increasingly related to innovation dynamics and evidence to lumpy growth [31] suggesting the absence of a solely rational expectation. Additionally, heavy tails indicated the occurrence of extreme events due to greater market opportunities for innovation dynamic [8].

Persistence (i.e. correlation) over time from innovation dynamics is also recognized by the literature as a distinct feature $[51,1,18]$. Technologies mature with time [23] and firms which have invested in innovation in the past are more likely to innovate in the future due to the perceived positive feedback [25] This endogenous and procyclical movement of adoption is consistent with the cyclical patterns of diffusion. Since diffusion of new technologies takes time, the cyclical response to news shock is highly persistent [27]. Numerical experiment and time series approaches provide the tools to study implications for the entrance of new technologies to the stock markets $[42,61]$.

Uncertainty and risk have been widely adopted. In any case, in the frame of this paper the interplay between them is strictly conceptually so that the frame of mind can be further nuanced.

Commonly, uncertainty is defined as the situation with unknown information about the environment [56] and risk derives from uncertainty by the intention to quantify. In other words, in this sense conceptually risk can be considered as a proxy for uncertainty. Innovation is an uncertain process where the outcomes are uncertain as well. This premise is not new and was already recognized by Frank Knight [48] and Keynes [47], as stated in Mazzucato's study [53]. Both economists used the concept of technological innovation as an example of true uncertainty. Based on this assumption, empirical works show that technology changes and period of technological changes lead to increased uncertainty and therefore to increased stock return volatility $[69,15,53]$. Technological innovations play a major role in explaining the long-term volatility observed in stock markets [42]. Excess volatility peaks precisely during periods associated to uncertainty [69], such as radical technological changes and therefore the fundamental information is less useful for making prediction about future values [72]. This entails to less information available and leads the market trend to be driven by other speculative investors heading them to "follow the crowd" instead of using their own fundamental data. This phenomenon is also known as "herd effect" and over-reaction [16].
In addition, the asymmetric information problem is studied within the innovation process context. All type of projects and certainly the ones related to new technology can generate a greater degree of asymmetric information, since managers have more knowledge about the state of the outcome compared to the outside [11]; as a result, stock return volatility increases. Especially high-tech firms suffer under the asymmetric information problem $[39,38,40,9]$. To offset the lack of information, high- tech firms organize conference calls and provide additional information about financial conditions to the public [71].

Another body of literature is the firm's approach level on high tech firms or frontier technologies firms in this frame of reference, which exhibit unjustifiably high stock return and volatility $[60,38,68]$. Evidence exists that return volatility is 2.21 percent higher for $R \& D$ intense firms compared to no $R \& D$ investing firms [19] and that the beta is twice higher for companies with intensive R\&D investment [49]. This makes sense in order to compensate the additional risk due to intensive $R \& D$ exposure leading to a significant premium [74].

To briefly recapitulate the goal of this article, we intend to empirically analyze the dynamic, time series properties of the correlations between daily log returns and the magnitude of the volatility transmissions from the emerging technologies to the representative indexes for the Spanish banking sector, the overall Spanish market and the finance industry in the EU area level.

As highlighted by Demirel and Mazzucato [29], new researches must focus on understating time series behaviors of innovation performance as well as considering the heterogeneous nature of technological innovation and performance variables.

To summarize, it is reasonable to explore the impact of emerging technologies on the Spanish banking sector, the Spanish market portfolio and the finance industry in the EU area volatility using a time series approach, given the volatility interpretation for innovation and dynamic processes under uncertainty and evaluating this relationship from the defined perspectives.

\section{Data and Methodology}

Since profits and growth rates are mainly used as reference for economic performance, then industry specific and a general market performance can be extrapolated through stock prices and financial market proxies' in levels and returns. 


\subsection{Data}

\subsubsection{Dependent performance variables}

This study utilizes a constructed BANK index (BANK) as proxy for the Spanish banking sector, the IBEX35 (IBEX) index as proxy for the overall Spanish market performance and the MSCI Europe Finance index (MSCI_EUR_FIN) as proxies for the financial industry in the Europe Area.

BANK is a reconstructed index that was calculated as proxy for the banking sector in Spain selecting the most representatives' Spanish banks in terms of Market Cap, and these are Banco de Sabadell, S.A. (SAB.MC), Banco Bilbao Vizcaya Argentaria, S.A. (BBVA.MC), Bankia, S.A. (BKIA.MC), Bankinter, S.A. (BKT.MC), CaixaBank, S.A. (CABK.MC) and Banco Santander, S.A. (SAN.MC). The expected price is calculated as a weighted sum of the individual assets' prices [66].

Information for the construction of the BANK index and IBEX was obtained from yahoo finance webpage. Information for the MSCI_EUR_FIN was retrieved from Investing webpage.

\subsubsection{Independent variables}

An equally weighted index was constructed denominates as TECH index which contains the ROBO Global Robotics \& Automation Index ETF (ROBO) $)^{2}$ and First Trust NASDAQ Cybersecurity ETF $(\mathrm{CIBR})^{3}$ as proxy to represent the emerging technology phenomena. In order to capture aside the emerging technology phenomena, associated risks and cyber risk awareness should also be tackled since Cybersecurity concerns financial institutions and can threaten the stability of financial markets [43]. Weighting the CIBR ETF and the ROBO ETF would provide additional deepness that contributes.

As Credit default swap (CDS), the ITRAXX Europe inde ${ }^{4}$ was selected as independent variable to expose the model against economic performance $[3,4,7]$. Information was obtained from Bloomberg.

The indices have been selected based on the completeness of data covering a sample period is from 8 July 2015 to 20 September 2019.

Daily data utilized is in the form of log returns on the price indices, the returns are in US dollars as calculated by the following formula:

2 Robo Global Robotics \& Automation Index ETF is an exchange-traded fund incorporated in the USA. The ETF seeks to track the performance of the ROBO Global Robotics and Automation Index (https://www.bloomberg.com/quote/ROBO:US).

${ }^{3}$ First Trust Nasdaq Cybersecurity ETF tracks the Nasdaq CTA Cybersecurity Index. The Index is designed to track the performance

$$
r_{t}=\ln \left(\frac{P_{t}}{P_{t-1}}\right)
$$

Information for the exchange rate USD vs EUR was obtained from Macrotrend webpage.

\subsection{Methodology}

The first methodology an GARCH modeling in order to determine volatility clustering. The ARCH model was the first of the GARCH family introduced by Engle in 1982. Furthermore, many extensions were developed such as the GARCH, EGARCH, IGARCH among others, these models being highly useful to estimate volatility.

The second stage evaluates the contagion of volatility between the dependent variables or proxies for the finance industry and the emerging technologies, through a multivariate GARCH as diagonal BEKK, to verify the results.

\subsubsection{ARMA}

The ARMA (autoregressive and moving average) stands for stationary structure and time discrete stochastic approach. This structure is useful to identify effects of the past of the series themselves as well as the MA effect that identifies signals send by the error term. We can represent an $\operatorname{ARMA}(p, q)$ model as:

$$
\begin{aligned}
& Y_{t}=\alpha_{o}+\alpha_{1} Y_{t-1}+\alpha_{2} Y_{t-2}+\cdots+\alpha_{p} Y_{t-p}+ \\
& \beta_{1} e_{t-1}+\beta_{2} e_{t-2}+\ldots+\beta_{q} e_{t-q}+e_{t}
\end{aligned}
$$

where $\left(e_{t}\right)=0 ; \operatorname{Var}\left(e_{t}\right)=\sigma^{2} ; \operatorname{Cov}\left(e_{t}, e_{t-h}\right)=0 \forall h \neq$ $0, p$ is number of lags of the dependent variable and $q$ the number of lags of the error term.

\subsection{2. $A R C H$}

Autoregressive conditional heteroskedastic (ARCH) introduced by Engel [33] has become a useful model to explain the behavior of asset return volatility over time, where the conditional variance can be represented as: of companies engaged in the Cyber security segment of the technology and industrial sectors (https://www.bloomberg.com/quote/CIBR:US)

${ }^{4}$ The ITRAXX Europe index that contains 125 equally weighted European names selected by a dealer poll based on CDS volume traded over the previous six months. (https://ihsmarkit.com/products/markit-itraxx.html) 


$$
\operatorname{Var}_{e_{t}} \equiv \sigma_{t}^{2}=\theta_{0}+\sum_{i=1}^{q} \theta_{i} e_{t-i}^{2}
$$

where $\mathrm{q}$ refers to the lag order of the squared error term include in the model. Under the consideration of the present analysis, in order to test the existence of an ARCH structure, the following set of the hypothesis will be tested:

$$
\begin{aligned}
& H_{0}: \theta_{1}=\theta_{2}=\cdots=\theta_{q}=0 \\
& H_{1}: \text { At least one } \theta \neq 0
\end{aligned}
$$

If the null hypothesis is rejected, this would imply that there is a structure for the volatility of the log price return. On the other hand, if the null is not rejected, that would imply stability for the volatility of the log prices returns.

\subsubsection{GARCH}

Bollerslev [12] introduced the generalized ARCH (GARCH) model, an extension of the ARCH model. The conditional variance, in function of its own lags, is given by:

$$
\operatorname{Var}_{e_{t}} \equiv \sigma_{t}^{2}=\theta_{0}+\sum_{i=1}^{q} \theta_{i} e_{t-i}^{2}+\sum_{j=1}^{p} \pi_{j} \sigma_{t-j}^{2}
$$

where $\theta_{0}>0$ and $\operatorname{GARCH}(p, q)$ is covariance stationary only if $\sum_{i=1}^{q} \theta_{\mathrm{i}}+\sum_{j=1}^{p} \pi_{j}<1$. It is important to notice that this is the structures used to model the volatility cluster once the dynamic of the variables was modelled with an ARMA structure.

\subsubsection{Diagonal BEKK}

The second stage evaluate the contagion of volatility between the dependent variables or proxies for the finance industry and the emerging technologies through the GARCH multivariate model.

Among the different possible specifications for the model, the BEKK specification, developed by Baba, Engle, Kraft and Kroner, which can be found in the study by Engle and Kroner [34] seems to fit best the multivariate extension of univariate $\mathrm{GARCH}$ for this purpose[20,21,22].

The diagonal BEKK model is given as

$$
H_{t}=W W^{\prime}+A e_{t-1}{ }^{\prime} A^{\prime}+B Q_{t-1} B^{\prime}(\mathrm{xx})
$$

where $\mathrm{A}$, and $\mathrm{B}$ are $\mathrm{N} \times \mathrm{N}$ matrices of parameter $\mathrm{W}$ is an upper triangular matrix of parameters. The Diagonal BEKK model is given as:

$$
\begin{array}{r}
H_{t}=W W^{\prime}+\operatorname{diag}(a) e_{t-1} \operatorname{diag}(a) \\
+\operatorname{diag}(b)^{\prime} Q_{t-1} \operatorname{diag}(b)
\end{array}
$$

$$
H_{t}=W^{\prime} W+\left(a a^{\prime}\right)^{\circ} e_{t-1} e_{t t-1}+\left(b b^{\prime}\right)^{\circ} H_{t-1}
$$

Aiming to reduce the number of parameters in the BEKK model, it is possible to apply a BEKK diagonal model, in which the matrices $A$ and B are diagonal. By reducing the number of parameters estimated by the model and since it is one of the most used in the literature for contagion overflow volatility [73] the diagonal BEKK specification was the application selected for this analysis.

McAleer [57] proved that the Quasi-Maximum Likelihood Estimators (QMLE) of the parameters of the diagonal or scalar BEKK models were consistent and asymptotically normal, so that standard statistical inference for testing hypotheses is valid.

\section{Empirical Results}

\subsection{Data Preliminaries}

Descriptive statistics for each $\log$ return between 7 July 2015 and 20 September 2019 are reported in Table 6 in the Appendix. Plots of daily prices and log returns for each variable are illustrated in Figure 1 and Figure 2. All return series display volatility clustering and leverage effects, making ARCH models applicable.

\subsubsection{Levels}

From Figure 1, where the involved series as represented at levels, we can observe similar trends or an association between BANK, IBEX and MSCI_EU_FIN. On the other hand, the CIBR Index and the Robo Index seems to follow and incremental trend. 

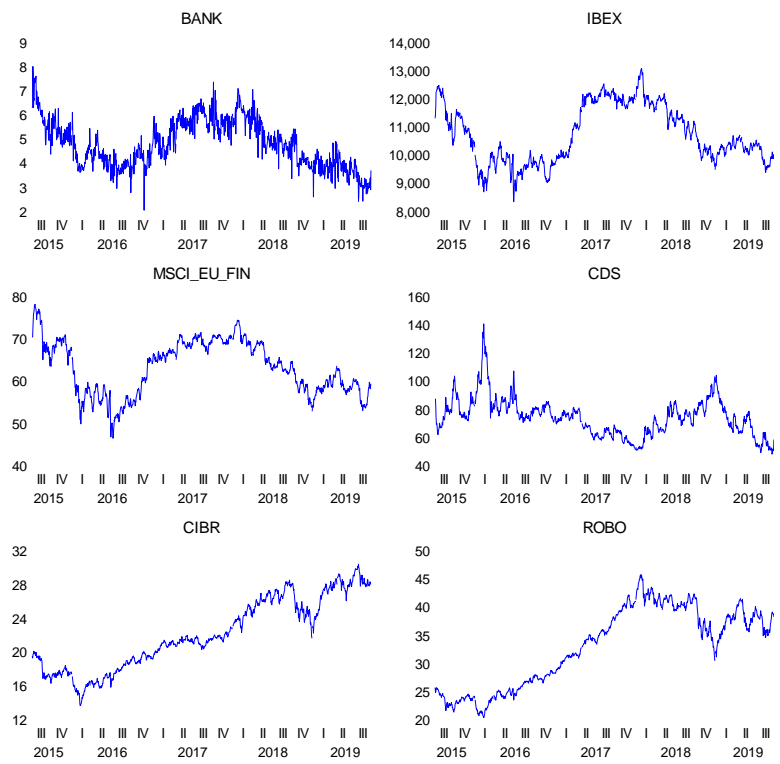

Fig. 1. BANK, IBEX, MSCI_EU_FIN, CDS, ROBO, CIBR at levels in the period 7 July 2015 to 20 September 2019.

\subsubsection{Logarithmic Returns}

From Figure 2, where the involved series are represented by logarithmic return level, two volatility clusters can be observed commonly during the period 2015 2016 and 2018 - 2019. Interestingly we can appreciate that during the first period, the most immediate impacted variable are MSCI_EU_FIN and IBEX and a lagged impacted over BANK. On the other hand, TECH is the most impacted varietal form the second volatility period. From Figure 2, we can observe volatility clustering specially during the 2015-2016 period for MSCI_EU_FIN. Interestingly all series retrieve an outlier during 2016 which can be linked to the rise of political risk driven by nationalism in 2016 around Europe as for example the Catalonian independence movement, the Brexit announcement among other events.
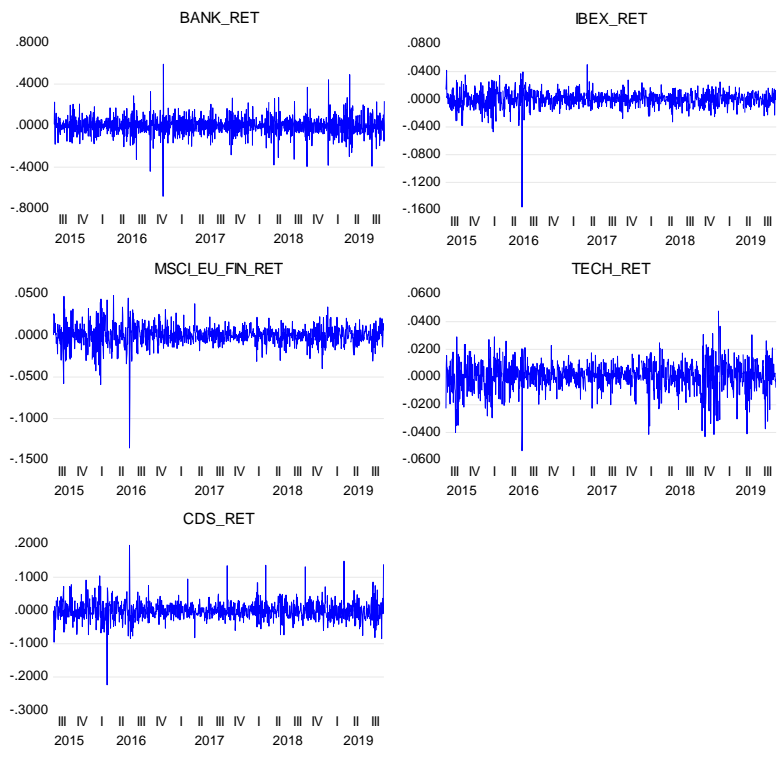

Fig. 2. Logarithmic returns of BANK, IBEX35, MSCI_EU_FIN and TECH in the period 8 July 2015 to 20 September 2019.

The logarithmic returns stay around zero as we can observe from Figure 2. The largest negative mean return $(-0.0483 \%)$ is for BANK whereas the IBEX has the lowest negative mean return $(-0.0111 \%)$. The kurtosis values of all index's returns are higher than three, thus the returns distribution could be fat-tailed. As the skewness values are negative, the skewness values are the asymmetric tail. Since the Jacque-Bera results are statistically significant and reject the null hypothesis of a normal distribution for all indices returns.

Nonetheless, our analysis is robust as models are usually robust as well in non-normal cases.

The correlation among the variables in its logarithmic return expression is reported in Table 7 in the Appendix. IBEX and MSCI_EUR_FIN have high correlations around 0.7900 . Interestingly our depended variables indicate differentiated correlation with TECH. Highest correlation between MSCI_EU_FIN and TECH with 0.52 and lowest with BANK with TECH at 0.0995.

\subsection{Unit Root Test}

We determined whether the analyzed series are stationary, employing the Augmented Dickey-Fuller (ADF) test, proposed by Dickey and Fuller [30] and the Phillips-Perron (PP) test, developed by Perron [62]. A stationary time series is mean-reverting and has a finite variance that guarantees that the process will never drift too far away from the mean.

Table 1 shows the results of the ADF test and PP test for the weekly logarithmic returns. The hypothesis of a 
unit root is rejected for all the variables at $90 \%, 95 \%$ and 99\% of confidence, which implies that the logarithmic returns of prices levels are stationary.

Table 1

Null hypothesis: Log return of indices

\begin{tabular}{|l|c|c|}
\hline Variable & $\begin{array}{c}\text { Augmented Dickey- } \\
\text { Fuller test statistics }(\mathrm{p}- \\
\text { value })\end{array}$ & $\begin{array}{c}\text { Phillips-Perron test } \\
\text { statistics (p-valeu) }\end{array}$ \\
\hline BANK & $-26.05192 * * *(0.0000)$ & $-110.2503 * * *(0.0001)$ \\
\hline IBEX & $-32.22969 * * *(0.0000)$ & $-32.43474 * * *(0.0000)$ \\
\hline MSCI_EU_FIN & $-30.82986 * * *(0.0000)$ & $-30.77527 * * *(0.0000)$ \\
\hline TECH & $-31.33133 * * *(0.0000)$ & $-31.33320 * * *(0.0000)$ \\
\hline CDS & $-30.28771 * * *(0.0000)$ & $-30.25784 * * *(0.0000)$ \\
\hline
\end{tabular}

Source: Eviews 10 University Version.

Notes: *significant at level of $10 \%, * *$ significant at level of $5 \%, * * *$ significant at level of $1 \%$.

Once we have determined that the variables are stationary, it is necessary to model their stochastic dynamics through ARMA structures. The results of modelling the stochastic dynamics of the different log returns through ARMA structures are presented in the following section.

\subsection{ARCH GARCH}

As indicated in the methodology GARCH model are estimated in order to capture volatility clustering among the performance variables for banking (BANK), overall Spanish market (IBEX) and finance industry in Europe (MSCI_EU_FIN) respectively as dependent variable from emerging technologies (TECH). In order to fulfill structure for the mean equation, CDS spread independent variable were included as proxy for economic performance. The results are represented in Table 2.

\subsubsection{Mean Equation}

First step is the mean equation model the coefficient for of TECH impacting on BANK is a positive significant 0.7560 , for IBEX is positive significant 0.2347 and for MSCI_EU_FIN is 0.2498 , indicating that there is a generalized positive impact from TECH on the performance variables all significant at $99 \%$ confidence. Nevertheless, it is interesting that coefficient of BANK is much higher, indicating that the Spanish banking sector is more impacted by the emerging technologies than the Spanish market as an overall. The associated coefficient of the CDS spread, widely used as an economic control variable, is slightly negative for all of the three cases and shows to be consistent with the literature $[26,5,10]$ since CDS market seems to lead the stock market [6].

\subsubsection{Variance Equation}

For the performance variables BANK, IBEX and MSCI_EU_FIN, presence of ARCH and GARCH effects are identified and in accordance with the literature $[27,15,59]$. A large sum of these coefficients implies that a large positive or a large negative logarithmic return will lead future forecasts of the variance to be high for a protracted period. The individual conditional variance coefficients are also as one would expect. The variance intercept is very small, own-volatility spillovers (ARCH effects) are relatively low while the coefficients on the lagged conditional variance or 'GARCH term' are large and significant at $99 \%$ confidence. The ARCH effect is higher for IBEX (0.1614) followed by MSCI_EU_FIN (0.1340) and for IBEX (0.147482) than for BANK (0.083350).

The GARCH coefficients suggest a positive impact from the volatility of TECH on the performance variables. The lagged own-volatility persistence (GARCH effects) is BANK (0.8144), IBEX (0.7477) and MSCI_EU_FIN (0.8173). These results suggest that BANK, IBEX and MSCI_EU_FIN derive their volatility persistence more from themselves. In other words, the large values GARCH effect for BANK, IBEX and MSCI_EU_FIN mean that large changes in the volatility will affect future volatility, and that volatilizes for a long period of time since the decay is slower. IBEX, compared to BANK and MSCI_EU_FIN, has a lower GARCH coefficient; in other words, the Spanish banking sector and the finance industry within the EU area will revert to equilibrium relatively slowly in the long run due to a shock in its volatilities perceived by a shock coming from emerging technology environment. On the other hand, IBEX can decay faster to its mean, which has interesting implication for an investor perspective. From the investor's perspective and in this context, this suggests what was expected regarding risk reduction purpose; an overall market indexes would be more recommended due to its diversified portfolio nature across industries. Moreover, the own volatility persistence effects for the performance variables modeled are within a tight range.

Additionally, the long-run average variance per day implied by the models are 0.0067 for BANK, $8.8552 \mathrm{E}$ 05 for IBEX and 9.8194E-05 for MSCI_EU_FIN. This corresponds to a total volatility per day is $8.20 \%$ for BANK, $0.99 \%$ for IBEX and $0.99 \%$ for MSCI_EU_FIN.

Table 2

Model results for the estimated GARCH model for BANK, IBEX, MSCI_EU_FIN

\begin{tabular}{|l|l|l|l|l|}
\hline & & BANK & IBEX & MSCI_EU_FIN \\
\hline & & Coefficient & Coefficient & Coefficient \\
\hline
\end{tabular}




\begin{tabular}{|c|c|c|c|}
\hline & (p-value $)$ & $(p$-value $)$ & (p-value) \\
\hline \multicolumn{4}{|c|}{ ARMA Model } \\
\hline Intercept & & & \\
\hline TECH & $\begin{array}{l}0.756059 \\
(0.0010) * * * *\end{array}$ & $\begin{array}{l}0.234705 \\
(0.0000)^{* * * *}\end{array}$ & $\begin{array}{l}0.249820 \\
(0.0000)^{* * * *}\end{array}$ \\
\hline TECH(-1) & - & $\begin{array}{l}0.148736 \\
(0.0000)^{* * *}\end{array}$ & - \\
\hline CDS & $\begin{array}{l}-0.194540 \\
(0.0402)^{* *}\end{array}$ & $\begin{array}{l}-0.145700 \\
(0.0000) * * *\end{array}$ & $\begin{array}{l}-0.200061 \\
(0.0000)^{* * *}\end{array}$ \\
\hline $\mathrm{AR}(1)$ & $\begin{array}{l}-0.591045 \\
(0.0000)^{* * * *}\end{array}$ & $\begin{array}{l}-0.075173 \\
(0.0185)^{* *}\end{array}$ & \\
\hline $\mathrm{AR}(2)$ & $\begin{array}{l}-0.378099 \\
(0.0000)^{* * *}\end{array}$ & & \\
\hline $\mathrm{AR}(3)$ & $\begin{array}{l}-0.296768 \\
(0.0000)^{* * *}\end{array}$ & & \\
\hline $\mathrm{AR}(4)$ & $\begin{array}{l}-0.129661 \\
(0.0000)^{* * * *}\end{array}$ & & \\
\hline $\mathrm{R}$ & 0.295545 & 0.378976 & 0.469274 \\
\hline \multicolumn{4}{|c|}{ Variance equation } \\
\hline Intercept & $\begin{array}{l}0.000687 \\
(0.0000)^{* * * *}\end{array}$ & $\begin{array}{l}8.94 \mathrm{E}-0.6 \\
(0.0000) * * *\end{array}$ & $\begin{array}{l}4.77-06 \\
(0.0000)^{* * *}\end{array}$ \\
\hline $\mathrm{ARCH}(1)$ & $\begin{array}{l}0.083350 \\
(0.0000)^{* * *}\end{array}$ & $\begin{array}{l}0.161469 \\
(0.0000)^{* * *}\end{array}$ & $\begin{array}{l}0.134063 \\
(0.0000)^{* * *}\end{array}$ \\
\hline GARCH(1) & $\begin{array}{l}0.814474 \\
(0.0000)^{* * * *}\end{array}$ & $\begin{array}{l}0.747786 \\
(0.0000) * * * *\end{array}$ & $\begin{array}{l}0.817362 \\
(0.0000)^{* * * *}\end{array}$ \\
\hline $\begin{array}{l}\text { Log Likeli- } \\
\text { hood }\end{array}$ & 1216.256 & 3556.996 & 3598.450 \\
\hline Akaike & -2.248150 & -6.592379 & -6.666884 \\
\hline Schwarz & -2.206425 & -6.559998 & -6.643772 \\
\hline $\begin{array}{l}\text { Hanna } \\
\text { Quinn }\end{array}$ & -2.232347 & -6.580116 & -6.658132 \\
\hline ARCH-LM & $\begin{array}{l}0.203783 \\
(0.9951) \\
\end{array}$ & $\begin{array}{l}0.006157 \\
(0.9375) \\
\end{array}$ & $\begin{array}{l}1.228455 \\
(0.2677) \\
\end{array}$ \\
\hline
\end{tabular}

\begin{tabular}{|l|l|c|}
\hline & $(0.0000)^{* * *}$ & \\
\hline $\mathrm{A} 1(1,1)$ & 0.281344 & 0.042790 \\
& $(0.0000)^{* * *}$ & \\
\hline $\mathrm{A} 1(2,2)$ & 0.360802 & 0.038163 \\
& $(0.0000)^{* * *}$ & \\
\hline $\mathrm{B} 1(1,1)$ & 0.869175 & 0.039692 \\
\hline $\mathrm{B} 1(2,2)$ & $(0.0000)^{* * *}$ & \\
& 0.916845 & 0.017646 \\
\hline
\end{tabular}

Source: Eviews 10 University Version.

Notes: *significant at level of $10 \%,{ }^{* *}$ significant at level of $5 \%, * * *$ significant at level of $1 \%$.

Notes: $\mathrm{GARCH}=\mathrm{M}+\mathrm{A} 1 * e_{t-1} * e_{t-1} * \mathrm{~A} 1+\mathrm{B} 1 * \mathrm{GARCH}_{t-1} \mathrm{~B} 1$, where $\mathrm{M}$ is an undefined matrix and $\mathrm{A} 1$ and $\mathrm{B} 1$ are diagonal matrices.

$\operatorname{GARCH}_{(B A N K)}=\mathrm{M}(1,1)+\mathrm{A} 1(1,1)^{2 *}\left(e \text { BANK }_{t-1}\right)^{2}+\mathrm{B} 1(1,1)^{2}$ *GARCH BANK $t-1$

$\mathrm{GARCH}_{(T E C H)}=\mathrm{M}(2,2)+\mathrm{A} 1(2,2)^{2} *\left(e \mathrm{TECH}_{t-1}\right)^{2}+\mathrm{B} 1(2,2)^{2}$ *GARCH TECH ${ }_{t-1}$

$\mathrm{COV}_{(B A N K, T E C H)}=\mathrm{M}(1,2)+\mathrm{A} 1(1,1) * \mathrm{~A} 1(2,2) *\left(e \operatorname{BANK}_{t-1}\right) *(e \mathrm{TECH}$ $\left.{ }_{t-1}\right)+\mathrm{B} 1(1,1) * \mathrm{~B} 1(2,2) *{ }_{(B A N K, T E C H) t-1}$

\section{Table 4}

Model results for the estimated diagonal BEKK for IBEX in the period 8 July 2015 to 20 September 2019

\begin{tabular}{|l|l|c|}
\hline Matrix & \multicolumn{1}{|c|}{$\begin{array}{c}\text { Coefficient } \\
(p \text {-value })\end{array}$} & Standard error \\
\hline $\mathrm{M}(1,1)$ & $\begin{array}{l}1.48 \mathrm{E}-05 \\
(0.0001)^{* * *}\end{array}$ & $3.76 \mathrm{E}-06$ \\
\hline $\mathrm{M}(1,2)$ & $\begin{array}{l}3.60 \mathrm{E}-06 \\
(0.0010) * * *\end{array}$ & $1.09 \mathrm{E}-06$ \\
\hline $\mathrm{M}(2,2)$ & $\begin{array}{l}5.06 \mathrm{E}-06 \\
(0.0006) * * *\end{array}$ & $1.48 \mathrm{E}-06$ \\
\hline $\mathrm{A} 1(1,1)$ & $\begin{array}{l}0.135591 \\
(0.0000)^{* * *}\end{array}$ & 0.028242 \\
\hline $\mathrm{A} 1(2,2)$ & $\begin{array}{l}0.088030 \\
(0.0000) * * *\end{array}$ & 0.019270 \\
\hline $\mathrm{B} 1(1,1)$ & $\begin{array}{l}0.115897 \\
(0.0000) * * *\end{array}$ & 0.021885 \\
\hline $\mathrm{EB} 1(2,2)$ & $\begin{array}{l}0.738018 \\
(0.0000) * * *\end{array}$ & 0.048311 \\
\hline
\end{tabular}

Notes: *significant at level of $10 \%, * *$ significant at level of $5 \%, * * *$ significant at level of $1 \%$.

\subsubsection{Diagonal BEKK}

The analysis of volatility series and volatility spillovers (contagion effect) in the context of the diagonal BEKK model is performed using the behavior of the conditional variance, conditional covariance and especially the conditional correlation.

This then provides us with estimates of the dynamic, also denominated time-varying co-movements between logarithmic returns of the variables.

Table 8, 9 and 10 in Appendix reports the estimates of the Mean Equation and Diagonal BEKK.

\section{Table 3}

Model results for the estimated diagonal BEKK for BANK in the period 8 July 2015 to 20 September 2019

\begin{tabular}{|c|l|c|}
\hline Matrix & \multicolumn{1}{|c|}{$\begin{array}{c}\text { Coefficient } \\
(p \text {-value })\end{array}$} & Standard error \\
\hline $\mathrm{M}(1,1)$ & $\begin{array}{l}0.000960 \\
(0.0000)^{* * *}\end{array}$ & 0.000328 \\
\hline $\mathrm{M}(1,2)$ & $\begin{array}{l}8.56 \mathrm{E}-06 \\
(0.0000)^{* * *}\end{array}$ & $5.71 \mathrm{E}-06$ \\
\hline $\mathrm{M}(2,2)$ & $4.87 \mathrm{E}-06$ & $1.68 \mathrm{E}-06$ \\
\hline
\end{tabular}

Source: Eviews 10 University Version.

Notes: *significant at level of $10 \%, * *$ significant at level of $5 \%, * * *$ significant at level of $1 \%$.

Notes: GARCH $=\mathrm{M}+\mathrm{A} 1 * e_{t-1} * e_{t-1} * \mathrm{~A} 1+\mathrm{B} 1 * \mathrm{GARCH}_{t-1} \mathrm{~B} 1$, where $\mathrm{M}$ is an undefined matrix and $\mathrm{A} 1$ and $\mathrm{B} 1$ are diagonal matrices.

$\mathrm{GARCH}_{(I B E X)}=\mathrm{M}(1,1)+\mathrm{A}_{(1,1)}{ }^{2 *}\left(e \operatorname{IBEX}_{t-1}\right)^{2}+\mathrm{B} 1(1,1)^{2}$ *GARCH IBEX ${ }_{t-1}$

$\mathrm{GARCH}_{(\mathrm{TECH})}=\mathrm{M}(2,2)+\mathrm{A} 1(2,2)^{2} *\left(e \mathrm{TECH}_{t-1}\right)^{2}+\mathrm{B} 1(2,2)^{2}$ *GARCH TECH T-I

$\operatorname{COV}_{(I B E X, T E C H)}=\mathrm{M}(1,2)+\mathrm{A} 1(1,1)^{*} \mathrm{~A} 1(2,2)^{*}\left(e \operatorname{IBEX}_{t-1}\right) *(e \mathrm{TECH}$ $\left.{ }_{t-1}\right)+\mathrm{B} 1(1,1)^{*} \mathrm{~B} 1(2,2)^{*}{ }_{(I B E X, T E C H)} t-1$

\section{Table 5}

Model results for the estimated diagonal BEKK for MSCI_EU_FIN in the period 8 July 2015 to 20 September 2019

\begin{tabular}{|c|l|c|}
\hline Matrix & $\begin{array}{c}\text { Coefficient } \\
(p-\text {-value })\end{array}$ & Standard error \\
\hline $\mathrm{M}(1,1)$ & $\begin{array}{l}5.26 \mathrm{E}-06 \\
(0.0000) * * *\end{array}$ & $9.94 \mathrm{E}-07$ \\
\hline $\mathrm{M}(1,2)$ & $1.73 \mathrm{E}-06$ & $4.51 \mathrm{E}-07$ \\
\hline
\end{tabular}




\begin{tabular}{|l|l|c|}
\hline & $(0.0001)^{* * *}$ & \\
\hline $\mathrm{M}(2,2)$ & $\begin{array}{l}3.51 \mathrm{E}-06 \\
(0.0001)^{* * *}\end{array}$ & $8.83 \mathrm{E}-07$ \\
\hline $\mathrm{A} 1(1,1)$ & $\begin{array}{l}0.324464 \\
(0.0000)^{* * *}\end{array}$ & 0.015612 \\
\hline $\mathrm{A} 1(2,2)$ & $\begin{array}{l}0.325214 \\
(0.0000)^{* * *}\end{array}$ & 0.019274 \\
\hline $\mathrm{B} 1(1,1)$ & $\begin{array}{l}0.928118 \\
(0.0000)^{* * *}\end{array}$ & 0.008194 \\
\hline $\mathrm{B} 1(2,2)$ & $\begin{array}{l}0.929163 \\
(0.0000)^{* * *}\end{array}$ & 0.009556 \\
& & \\
\hline
\end{tabular}

Source: Eviews 10 University Version

Notes: *significant at level of $10 \%, * *$ significant at level of $5 \%, * * *$ significant at level of $1 \%$.

Notes: $\mathrm{GARCH}=\mathrm{M}+\mathrm{A} 1 * e_{t-1} * e_{t-1}{ }^{*} \mathrm{~A} 1+\mathrm{B} 1 * \mathrm{GARCH}_{t-1} \mathrm{~B} 1$, where $\mathrm{M}$ is an undefined matrix and $\mathrm{A} 1$ and $\mathrm{B} 1$ are diagonal matrices.

$\mathrm{GARCH}_{(\text {MSCI_EUROPE_FIN })}=\mathrm{M}(1,1)+\mathrm{A} 1(1,1){ }^{2} *(e$ MSCI_EU ROPE_FIN $\left._{t-1}\right)^{2}+\mathrm{B} 1(1,1)^{2} * \mathrm{GARCH}^{2}$ MSCI_EU_FIN ${ }_{t-1}$

$\mathrm{GARCH}_{(T E C H)}=\mathrm{M}(2,2)+\mathrm{A} 1(2,2)^{2} *\left(e \text { TECH }{ }_{t-1}\right)^{2}+\mathrm{B} 1(2,2)^{2}$ *GARCH TECH ${ }_{t-1}$

$\mathrm{COV}\left(\right.$ MSCI_EU_FIN, $_{\text {TECH }}=\mathrm{M}(1,2)+\mathrm{A} 1(1,1) * \mathrm{~A} 1(2,2)^{*}(e$ MSCI_EU_FIN $\left.{ }_{t-1}\right) *\left(e \mathrm{TECH}_{t-1}\right)+\mathrm{B} 1(1,1) * \mathrm{~B} 1(2,2) *{ }_{\left(M S C I E U \_F I N, T E C H\right.}$ $t-1$

Wald Test is performed for the coefficient associated to TECH, in order to test the null hypothesis, which states that mean spillovers from TECH equal zero. The null can be rejected for all associated coefficient for the three models. In the context of the diagonal BEKK model, the analysis of the conditional covariance and conditional correlation between two or more assets effectively allows the evaluation of the contagion effect.

Conditional variance-covariance equations effectively capture the volatility and cross volatility because most coefficients are statistically significant (see Table 6 in the Appendix). The conditional variances-covariances implied by the Diagonal BEKK Specification are presented below.

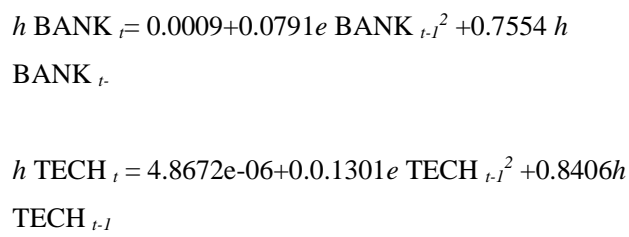

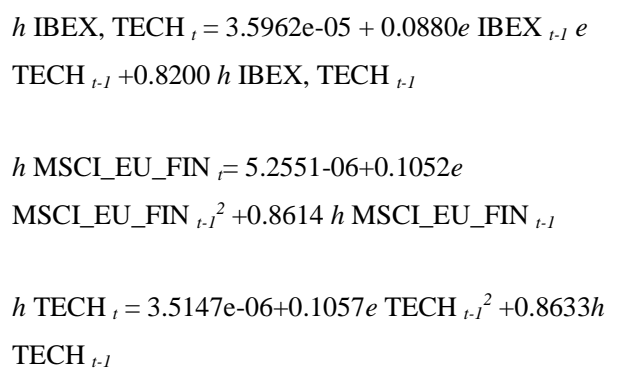

From these empirical results we conclude a strong evidence of GARCH effect and the presence of a weaker $\mathrm{ARCH}$ effect, results that are in line with the previous methodology applied.

Results of conditional mean return show a statistically significant covariation in shocks, which depends more on its lags than on past errors. Consequently, the shocks for the Spanish banking sector, Spanish market and MSCI_EU_FIN are influenced by past information.

These coefficients show the volatility persistence for each dependent variable in terms of its own past errors. Equations show a statistically significant covariation in shocks, which depends more on its lags than on past errors.

In terms of cross-volatility spillover (ARCH) is less then cross-volatility persistence $(\mathrm{GARCH})$ and in lines with the results obtained with the previous methodology. TECH have the greatest ARCH effect for BANK (0.1101) followed by IBEX (0.0880) and MSCI_EU_FIN (0.1055), even though the coefficient is relatively close.

Cross-volatility persistence as past volatility shocks in TECH have large effects on the future volatility of MSCI_EU_FIN (0.8623) followed by IBEX (0.8200) and BANK (0.7968); nevertheless, for BANK the associated coefficient is lower.

It is an important finding here that although cross-volatility spillover and cross-volatility persistence are relatively close across the three performance variables.

The plots for the conditional variances-covariances estimated by the Diagonal BEKK Model are illustrated in Figure 3, Figure 4 and Figure 5. They suggest that the movements display an extremely volatile trend for the study period.

Moreover, from Figure 6 we can observe that the conditional correlations show sharp increases at some point 
during 2015-2016 and period during 2018-2019 for each pair of variables. Known exogenous factors have shown to be the root causes. The first period of high volatility is related to political risk driven by nationalism in 2016 around Europe. The highest peak was experienced by IBEX and MSCI_EU_FIN during the first period of high volatility with a conditional correlation of 0.8107 and 0.9370 respectively, as maximum values presented over the entire studied period. BANK experienced a maximum conditional correlation of 0.6730 . The results are aligned with political risk across Europe as the caused uncertainty with continuously cause high instability in key financial markets. The second period of high volatility be investor to weight the prospect of global trade tensions and excessive debt.

This provides evidence that the linkages between examined dependent variables with the emerging technology phenomena highly integrated and that volatility spillovers rise during period of high volatility.

The Ljung-Box Q statistics show no evidence of autocorrelation in the standardized residuals (see Table 11, Table 12 and Table 13 in Appendix). It can be concluded that the conditional mean return equations are correctly specified with the diagonal BEKK GARCH model.
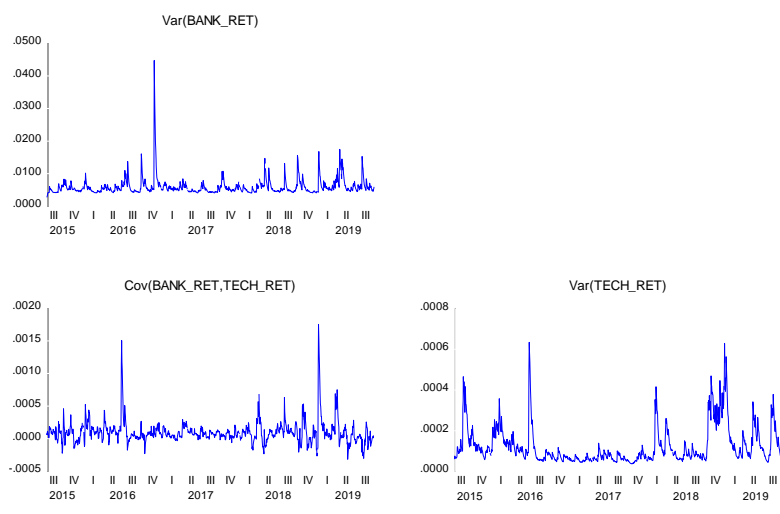

Fig. 3. Variance and Conditional Covariance for logarithmic returns for BANK and TECH in the period 8 July 2015 to 20 September 2019.
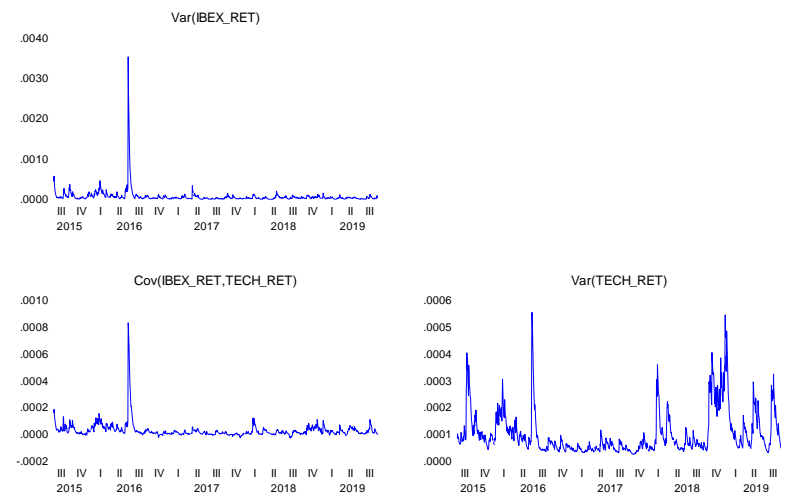

Fig. 4. Variance and Conditional Covariance for logarithmic returns for IBEX and TECH in the period 8 July 2015 to 20 September 2019
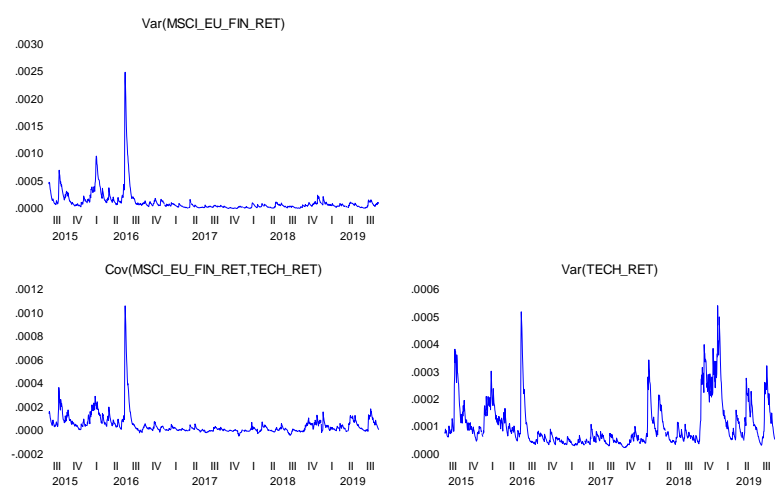

Fig. 5. Variance and Conditional Covariance for logarithmic returns for MSCI_EU_FIN and TECH in the period 8 July 2015 to 20 September 2019.

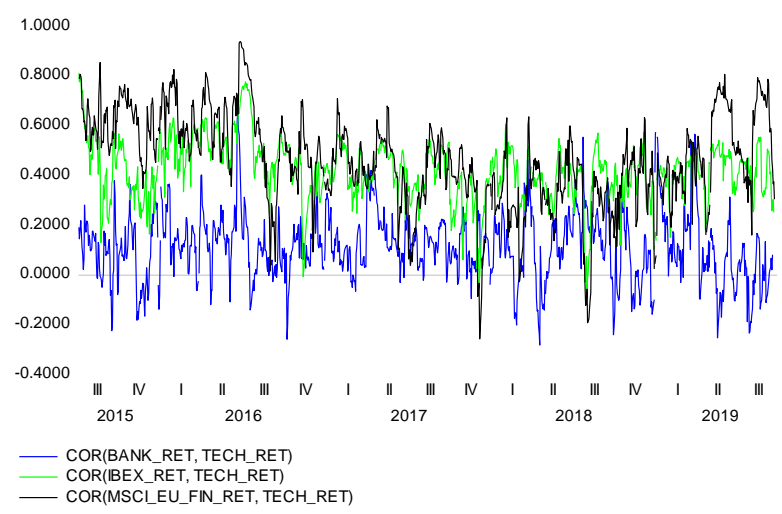

Fig. 6. Conditional Correlation of the logarithmic returns of BANK and TECH, IBEX and TECH and MSCI_EU_FIN and TECH in the period 8 July 2015 to 20 September 2019. 


\section{Conclusion}

This article investigates the dynamic, time series properties of the correlations, volatility cluster, spillover and persistence for daily log returns as for three performance variables and emerging technology phenomena with the objective to study the impact on Spanish banking sector (BANK), the Spanish market portfolio (IBEX) and the finance industry in the European Union Area (MSCI_EUR_FIN). An equally weighted index was constructed as proxy to represent the emerging technology phenomena using the ROBO Global Robotics \& Automation Index ETF (ROBO) and First Trust NASDAQ Cybersecurity ETF (CIBR). Credit default swap (CDS) as proxy was incorporated to control for the economy-wide risk. The indices have been selected based on the completeness of data covering a sample period from 7 July 2015 to 20 September 2019. Daily log returns were calculated. The generalized autoregressive conditional heteroskedasticity GARCH methodology was applied followed by a diagonal BEKK approach. Descriptive statistics of our series showed stationary nature as confirmed by the Dickey and Fuller [30], and the Phillips-Perron test [62] which implies that the logarithmic returns of prices levels are stationary. Also, volatility clustering where identified. In this sense the proposed methodologies seems to fit most for this purpose.

Broadly, the results confirm that emerging technology environment is important in capturing the level of risk for the three performance variables return and volatility context. The results of the estimated models within the mentioned methodologies are in line.

Resulting from the first methodology applied, the associated coefficient for the emerging technology is positive and statistically significant for all three performance variables. The magnitude indicates that the Spanish banking sector (BANK) is much more impacted by the emerging technologies (TECH) than the Spanish market as an overall (IBEX). These results suggest that an increase in log returns of the Spanish banking sector is significantly associates with the performance of emerging technology phenomena.

The variance equation provide insight about the volatility dynamics. The ARCH effect is relatively low compared to GARCH for the performance variables, indicating that they will recover its equilibrium volatility level slowly after a shock from emerging technology environment was perceived. However, the ARCH is slightly higher for Spanish market index, suggesting that they decay faster to its equilibrium volatility level compared to the Spanish banking sector and the finance industry in the EU area.
In the context of the diagonal BEKK model, the analysis of the conditional covariance and conditional correlation between two or more variables effectively allows the evaluation of the contagion effect. In term of cross volatility conditions, the ARCH effect is relatively low compared to GARCH, tough a slow decay and slow regression toward the mean is perceived. The results indicate that contagion from the emerging technology environment $(\mathrm{TECH})$ to the performance variable exists through cross-volatilities spillover and cross-volatilities persistence. The contagion of shocks emitted from the technology phenomena are relatively similar among the performance variables, being the Spanish banking sector slightly more impacted, regardless with the ability to revert faster to its cross-volatilities equilibrium compared to the other performance variables. The Spanish banking sector and the finance industry at regional EU level will revert to its cross-volatilities equilibrium relatively slowly given a shock coming from emerging technology environment (TECH). Shock from emerging technology will most persist at the finance industry at EU area level. These results provide interesting implication for an investor perspective and confirms the need to further explore the impact of emerging technologies in different sectors and industries.

Additionally, two volatility clustering periods where identified withing an sharp increase in conditional variance-covariance estimated by the diagonal BEKK model. This provides evidence that the linkages between examined performance variables with the emerging technology phenomena is highly integrated and that volatility spillovers rise during period of high volatility.

One important implication of this study is that adding stocks from the performance variables will not diversify necessarily the portfolio risk away. Investors must diversify their portfolios towards different risk profile components. The results also evidence that for risk reduction purpose an overall market standpoint would be more recommended due to is diversified portfolio nature across industries.

The work reviews in this article provide results on correlations, volatility spillover and persistence effects between emerging technologies and performance variables that must be considered. Sector, industry and market specific features must be contemplated and can result in heterogeneous insights about the relationship between emerging technology phenomena and performance variables.

The need to understand the time series behavior is highlighted at this stage and opens a key area for future research as a feature of persistence and diffusion nature of innovation and emerging technology context. This, in fact, implies that more work needs to be delimited by 
the gap between the concept of risk and uncertainty in order to apply more suitable numerical approaches.

\section{References}

[1] Alfranca, O., Rama, R., and von Tunzelmann, N. (2002). A patent analysis of global food and beverage firms: the persistence of innovation. Agribusiness: An International Journal, 18(3), 349368.

[2] Alfranca, O., Rama, R., and von Tunzelmann, N. (2002). A patent analysis of global food and beverage firms: the persistence of innovation. Agribusiness: An International Journal, 18(3), 349368.

[3] Augustin, P., Subrahmanyam, M. G., Tang, D. Y., and Wang, S. Q. (2014). Credit default swaps: A survey. Foundations and Trends ${ }^{\circledR}$ in Finance, 9(1-2), 1-196.

[4] Augustin, P., Subrahmanyam, M. G., Tang, D. Y., and Wang, S. Q. (2016). Credit default swaps: Past, present, and future. Annual Review of Financial Economics, 8, 175-196.

[5] Aunon-Nerin, D., Cossin, D., Hricko, T., and Huang, Z. (2002) Exploring for the Determinants of Credit Risk in Credit Default Swap Transaction Data: Is Fixed-Income Markets' Information Sufficient to Evaluate Credit Risk?. FAME Research Paper, (65).

[6] Apergis, N., and Andreas, L. A. K. E. (2010). Credit default swaps and stock prices: Further evidence of mean and volatility transmission using a GARCH-M model. China-USA Business Review, 9 (11), 1-22.

[7] Arce, O., Mayordomo, S., and Peña, J. I. (2013). Credit-risk valuation in the sovereign CDS and bonds markets: Evidence from the euro area crisis. Journal of International Money and Finance, $35,124-145$.

[8] Axtell, R. L. (2001). Zipf distribution of US firm sizes. science, 293(5536), 1818-1820.

[9] Barron, O. E., Byard, D., Kile, C., and Riedl, E. J. (2002). Hightechnology intangibles and analysts' forecasts. Journal of Accounting Research, 40(2), 289-312.

[10]Blanco, R., Brennan, S., and Marsh, I. W. (2004). An empirical analysis of the dynamic relationship between investment grade bonds and credit default swaps.

[11]Blazenko, G. W. (1987). Managerial preference, asymmetric information, and financial structure. The journal of finance, 42(4), 839-862.

[12] Bollerslev, T. (1986). Generalized autoregressive conditional heteroskedasticity. Journal of econometrics, 31(3), 307-327.

[13] Breschi, S., Malerba, F., and Orsenigo, L. (2000). Technological regimes and Schumpeterian patterns of innovation. The economic journal, 110(463), 388-410.

[14]Campanella, F., Della Peruta, M. R., and Del Giudice, M. (2017) The effects of technological innovation on the banking sector. Journal of the Knowledge Economy, 8(1), 356-368.

[15] Campbell, J. Y., Lettau, M., Malkiel, B. G., \& Xu, Y. (2001) Have individual stocks become more volatile? An empirical exploration of idiosyncratic risk. The Journal of Finance, 56(1), 143.

[16] Campbell, J. Y., Shiller, R. J. (1988). Stock prices, earnings, and expected dividends. The Journal of Finance, 43(3), 661-676.

[17] Castellacci, F. (2008). Innovation and the competitiveness of industries: Comparing the mainstream and the evolutionary approaches. Technological Forecasting and Social Change, 75(7), 984-1006.

[18]Cefis, E. (2003). Is there persistence in innovative activities? International Journal of Industrial Organization, 21(4), 489-515.

[19]Chan, L. K., Lakonishok, J., \& Sougiannis, T. (2001). The stock market valuation of research and development expenditures. The Journal of Finance, 56(6), 2431-2456.

[20]Chang, C. L., McAleer, M., \& Zuo, G. (2017). Volatility spillovers and causality of carbon emissions, oil and coal spot and futures for the EU and USA. Sustainability, 9(10), 1789.

[21]Chang, C. L., \& McAleer, M. (2018). The fiction of full BEKK: Pricing fossil fuels and carbon emissions. Available at SSRN 3135899.

[22]Chang, C. L., Li, Y., \& McAleer, M. (2015). Volatility spillovers between energy and agricultural markets: A critical appraisal of theory and practice (No. TI 15-077/III).

[23] Christensen, C. M. (1992). Exploring the limits of the technology S-curve. Part I: component technologies. Production and operations management, 1(4), 334-357.

[24]Coeckelbergh, M. (2016). Money machines: Electronic financial technologies, distancing, and responsibility in global finance. Routledge.

[25]Cohen, W. M., \& Levinthal, D. A. (1989). Innovation and learning: the two faces of R \& D. The economic journal, 99(397), 569596.

[26]Collin-Dufresn, P., Goldstein, R. S., \& Martin, J. S. (2001). The determinants of credit spread changes. The Journal of Finance, 56(6), 2177-2207.

[27]Comin, D. (2009). On the integration of growth and business cycles. Empirica, 36(2), 165-176.

[28]Cozzens, S., Gatchair, S., Kang, J., Kim, K. S., Lee, H. J. Ordóñez, G., \& Porter, A. (2010). Emerging technologies: quantitative identification and measurement. Technology Analysis \& Strategic Management, 22(3), 361-376.

[29]Demirel, P \& Mazzcauto, M. (2013). Innovation and economic performance (industrila and financial): research results and questions for future research in Innovation and Finance. Routledge, pp. $46-68$.

[30]Dickey, D. A., \& Fuller, W. A. (1981). Likelihood ratio statistics for autoregressive time series with a unit root. Econometrica: journal of the Econometric Society, 1057-1072.

[31]Dosi, G. (2005). Statistical regularities in the evolution of industries: a guide through some evidence and challenges for the theory (No. 2005/17). LEM working paper series.

[32]ECB, 2019. Innovation and its impact on the European retail payment landscape. Note by the ECB for the Economic and Financial Affairs Council, december 2019. Retrievd janruary 2020.

[33] Engle, R. F. (1982). Autoregressive conditional heteroscedasticity with estimates of the variance of United Kingdom inflation. Econometrica: Journal of the Econometric Society, 987-1007.

[34]Engle, R. F., \& Kroner, K. F. (1995). Multivariate simultaneous generalized ARCH. Econometric theory, 11(1), 122-150.

[35]Fama, E. F. (1965). The behavior of stock-market prices. The journal of Business, 38(1), 34-105.

[36] Freeman, C. (1995). The 'National System of Innovation'in historical perspective. Cambridge Journal of economics, 19(1), 524.

[37] Geroski, P., Machin, S., \& Van Reenen, J. (1993). The profitability of innovating firms. The RAND Journal of Economics, 198211. 
[38] Gharbi, S., Sahut, J. M., \& Teulon, F. (2014). R\&D investments and high-tech firms' stock return volatility. Technological Forecasting and Social Change, 88, 306-312.

[39] Gu, F., \& Li, J. Q. (2007). The credibility of voluntary disclosure and insider stock transactions. Journal of Accounting Research, 45(4), 771-810.

[40] Gu, F., \& Wang, W. (2005). Intangible assets, information complexity, and analysts' earnings forecasts. Journal of Business Finance \& Accounting, 32(9-10), 1673-1702.

[41]Guo, Y., \& Liang, C. (2016). Blockchain application and outlook in the banking industry. Financial Innovation, 2(1), 24.

[42] Iraola, M. A., \& Santos, M. S. (2007). Technological waves in the stock market.

[43] Johnson, K. N. (2015). Cyber risks: Emerging risk management concerns for financial institutions. Ga. L. Rev., 50, 131.

[44] Jovanovic, B., \& P. L. Rousseau (2001).” Vintage Organization Capital," NBER Working Paper No. 8166.

[45] Jovanovic, B., \& MacDonald, G. M. (1994). The life cycle of a competitive industry. Journal of Political Economy, 102(2), 322347.

[46] Kearney, C., \& Potì, V. (2008). Have European stocks become more volatile? An empirical investigation of idiosyncratic and market risk in the Euro area. European Financial Management, 14(3), 419-444.

[47] Keynes, J. M. (1973). The collected writings of JM Keynes.

[48] Knight Frank, H. (1921). Risk, uncertainty and profit. Houghton Mifflin, Boston

[49]Lantz, J. S., \& Sahut, J. M. (2005). R\&D investment and the financial performance of technological firms. International Journal of Business, 10(3), 251.

[50]Lucas Jr, R. E. (1988). On the mechanics of economic development. Journal of monetary economics, 22(1), 3-42.

[51] Malerba, F., Orsenigo, L., \& Peretto, P. (1997). Persistence of innovative activities, sectoral patterns of innovation and international technological specialization. International Journal of Industrial Organization, 15(6), 801-826.

[52] Malkiel, B. G., \& Fama, E. F. (1970). Efficient capital markets: A review of theory and empirical work. The journal of Finance, 25(2), 383-417.

[53] Mazzucato, M. (2006). Innovation and stock prices: a review of some recent work. Revue de l'OFCE, (5), 159-179.

[54] Mazzucato, M., and Tancioni, M. (2008). Stock Price Volatility and Patent Citation Dynamics: the case of the pharmaceutical industry.

[55] Mazzucato, M., and Tancioni, M. (2012). R\&D, patents and stock return volatility. Journal of Evolutionary Economics, 22(4), 811832.

[56] Merigó, J. M., Gil-Lafuente, A. M., \& Gil-Lafuente, J. (2016). Business, industrial marketing and uncertainty. Journal of Business \& Industrial Marketing, 31(3), 325-327.

[57] McAleer, M., Chan, F., Hoti, S., \& Lieberman, O. (2008). Generalized autoregressive conditional correlation. Econometric Theory, 24(6), 1554-1583.

[58]Mishkin, Frederic S. 2016. The Economics of Money, Banking, and Financial Markets. Eleventh Edition (Global Edition). Harlow: Pearson.

[59] Pástor L, Veronesi P (2005) Technological revolutions and stock returns. National Bureau of Economic Research w11876

[60]Pástor, L., \& Veronesi, P. (2006). Was there a Nasdaq bubble in the late 1990s? Journal of Financial Economics, 81(1), 61-100.
[61]Pástor, L., \& Veronesi, P. (2009). Technological revolutions and stock prices. American Economic Review, 99(4), 1451-83.

[62]Perron, P. (1997). Further evidence on breaking trend functions in macroeconomic variables. Journal of econometrics, 80(2), 355-385.

[63] Ratten, V. (2008). Technological innovations in the m-commerce industry: A conceptual model of WAP banking intentions. The Journal of High Technology Management Research, 18(2), 111117.

[64]Rishi, M., \& Saxena, S. C. (2004). Technological innovations in the Indian banking industry: the late bloomer. Accounting, Business \& Financial History, 14(3), 339-353.

[65] Romer, P. M. (1990). Endogenous technological change. Journal of political Economy, 98(5, Part 2), S71-S102.

[66] Ross, S. Westerfield, R. and Jaffe, J. (2002). Capital market theory: An overview. Corporate finance (6th ed.) (226-247). New York, NY: McGraw-Hill.

[67] Rotolo, D., Hicks, D., and Martin, B. R. (2015). What is an emerging technology? Research Policy, 44(10), 1827-1843.

[68] Schwert, G. W. (2002). Stock volatility in the new millennium: how wacky is Nasdaq? Journal of Monetary Economics, 49(1), 3 26.

[69] Shiller, R. C. (2000). Irrational exuberance. Philosophy and Public Policy Quarterly, 20(1), 18-23.

[70] Schwab, K. (2017). The fourth industrial revolution. Currency.

[71]Tasker, S. C. (1998). Bridging the information gap: Quarterly conference calls as a medium for voluntary disclosure. Review of Accounting Studies, 3(1-2), 137-167.

[72]Tushman, M. L., and O'Reilly III, C. A. (1996). Ambidextrous organizations: Managing evolutionary and revolutionary change. California management review, 38(4), 8-29.

[73] Vartanian, P. (2018). Is There a Possibility of Diversification Between Commodities and Ibovespa? Analysis of Volatility Transmission (2000-2016). Analysis of Volatility Transmission (2000 2016) (December 16, 2018).

[74]Wedig, G. J. (1990). How Risky is R and D? A Financial Approach. The Review of Economics and Statistics, 296-303.

[75]Wiener, J. B. (2004). The regulation of technology, and the technology of regulation. Technology in Society, 26(2-3), 483-500.

[76]Zetzsche, D. A., Buckley, R. P., Barberis, J. N., \& Arner, D. W. (2017). Regulating a revolution: From regulatory sandboxes to smart regulation. Fordham J. Corp. \& Fin. L., 23, 31. 


\section{Appendix}

\section{Table 6}

Descriptive statistics of the logarithmic returns of BANK, IBEX, MSCI_EUR_FIN and TECH in the period 8 July 2015 to 20 September 2019

\begin{tabular}{|l|l|l|l|l|}
\hline & \multicolumn{1}{|c|}{ BANK } & \multicolumn{1}{|c|}{ IBEX } & $\begin{array}{c}\text { MSCI_EU_ } \\
\text { FIN }\end{array}$ & \multicolumn{1}{c|}{ TECH } \\
\hline Mean & -0.000483 & -0.000111 & -0.000157 & 0.000348 \\
\hline Median & $-1.49 \mathrm{E}-05$ & 0.000299 & 0.000000 & 0.001019 \\
\hline Maximum & 0.591772 & 0.049841 & 0.047936 & 0.047870 \\
\hline Minimum & -0.679932 & -0.155674 & -0.135393 & -0.053353 \\
\hline Std. Dev. & 0.094927 & 0.012035 & 0.012951 & 0.010755 \\
\hline Skewness & -0.150312 & -2.036759 & -1.262044 & -0.636995 \\
\hline Kurtosis & 9.158410 & 29.12856 & 16.13983 & 5.418643 \\
\hline Jarque-Bera & 1707.570 & 31410.02 & 8041.256 & 335.6571 \\
\hline Probability & 0.000000 & 0.000000 & 0.000000 & 0.000000 \\
\hline Sum & -0.520426 & -0.119318 & -0.168939 & 0.374945 \\
\hline Sum Sq. Dev. & 9.704950 & 0.156003 & 0.180635 & 0.124572 \\
\hline Observations & 1078 & 1078 & 1078 & 1078 \\
\hline
\end{tabular}

Table 7

Correlation analysis of the logarithmic returns of BANK, IBEX, MSCI_EUR_FIN and TECH in the period 8 July 2015 to 20 September 2019

\begin{tabular}{|l|c|c|c|c|}
\hline & BANK & IBEX & $\begin{array}{c}\text { MSCI_EU_ } \\
\text { FIN }\end{array}$ & TECH \\
\hline BANK & 1.000000 & 0.183201 & 0.163659 & 0.099557 \\
\hline IBEX_ & 0.183201 & 1.000000 & 0.790043 & 0.469432 \\
\hline MSCI_EU_FIN & 0.163659 & 0.790043 & 1.000000 & 0.521006 \\
\hline TECH & 0.099557 & 0.469432 & 0.521006 & 1.000000 \\
\hline
\end{tabular}

Table 8

Report the estimates of the Mean Equation and Diagonal BEKK for BANK

\begin{tabular}{|c|c|c|}
\hline & BANK & TECH \\
\hline & $\begin{array}{c}\text { Coefficient } \\
\text { (p-value) } \\
\text { [Std error] }\end{array}$ & $\begin{array}{c}\text { Coefficient } \\
\text { (p-value) } \\
\text { [Std error] }\end{array}$ \\
\hline Intercept & & $\begin{array}{l}0.000986 \\
(0.0001)^{* * *} \\
{[0.000250]}\end{array}$ \\
\hline $\mathrm{TECH}_{\mathrm{t}-1}$ & $\begin{array}{l}0.372708 \\
(0.0946)^{*} \\
{[0.222995]}\end{array}$ & \\
\hline $\mathrm{CDS}_{\mathrm{t}-1}$ & $\begin{array}{l}-0.118810 \\
(0.1445)\end{array}$ & \\
\hline BANK $_{t-1}$ & $\begin{array}{l}-0.596974 \\
(0.0000)^{* * *} \\
{[0.081412]}\end{array}$ & \\
\hline BANK $_{\mathrm{t}-2}$ & $\begin{array}{l}-0.368099 \\
(0.0000)^{* * * *}\end{array}$ & \\
\hline
\end{tabular}

\begin{tabular}{|l|l|l|}
\hline & {$[0.032600]$} & \\
& & \\
\hline BANK $_{\mathrm{t}-3}$ & -0.276393 & \\
& $(0.0000)^{* * *}$ & \\
& {$[0.030414]$} & \\
\hline BANK $_{\mathrm{t}-4}$ & -0.144721 & \\
& $(0.0000)^{* * *}$ & \\
& {$[0.027340]$} & \\
\hline
\end{tabular}

Source: Eviews 10 University Version.

Notes: *significant at level of $10 \%,{ }^{* *}$ significant at level of $5 \%, * * *$ significant at level of $1 \%$.

Notes: BANK $_{t=} T E C H_{t-1}++\mathrm{CDS}_{t-1}+\mathrm{BANK}_{t-1}+\mathrm{BANK}_{t-2}+\mathrm{BANK}^{-1}$ $t_{t-3}+\mathrm{BANK}_{t-4}$

$\mathrm{TECH}_{t=\mathrm{C}}$

Table 9

Report the estimates of the Mean Equation and Diagonal BEKK for IBEX

\begin{tabular}{|c|c|c|}
\hline & $I B E X$ & TECH \\
\hline & $\begin{array}{c}\text { Coefficient } \\
\text { (p-value) } \\
\text { [Std error] }\end{array}$ & $\begin{array}{c}\text { Coefficient } \\
\text { (p-value) } \\
\text { [Std error] }\end{array}$ \\
\hline Intercept & & $\begin{array}{l}0.000973 \\
(0.0000)^{* * *} \\
{[0.000233]}\end{array}$ \\
\hline $\mathrm{TECH}_{\mathrm{t}-1}$ & $\begin{array}{l}0.216567 \\
(0.0000)^{* * *} \\
{[0.029507]}\end{array}$ & \\
\hline $\mathrm{TECH}_{\mathrm{t}-2}$ & $\begin{array}{l}0.005749 \\
(0.8223) \\
{[0.025604]}\end{array}$ & \\
\hline $\operatorname{CDS}_{t-1}$ & $\begin{array}{l}0.002731 \\
(0.8159) \\
{[0.011729]}\end{array}$ & \\
\hline $\operatorname{IBEX}_{\mathrm{t}-1}$ & $\begin{array}{l}-0.108293 \\
(0.0014)^{* * *} \\
{[0.033812]}\end{array}$ & \\
\hline
\end{tabular}

Source: Eviews 10 University Version.

Notes: *significant at level of $10 \%, * *$ significant at level of $5 \%, * * *$ significant at level of $1 \%$.

Notes: $\mathrm{IBEX}_{t=} \mathrm{TECH}_{t-1+} \mathrm{TECH}_{t-2+} \mathrm{CDS}_{t-1+1} \mathrm{IBEX}_{t-1} ; \mathrm{TECH}_{t=\mathrm{C}}$

Table 10

Report the estimates of the Mean Equation and Diagonal BEKK for MSCI EU FIN

\begin{tabular}{|c|c|c|}
\hline & $M S C I \_E U \_F I N$ & TECH \\
\hline & $\begin{array}{c}\text { Coefficient } \\
\text { (p-value }) \\
\text { [Std error] }\end{array}$ & $\begin{array}{c}\text { Coefficient } \\
\text { (p-value) } \\
\text { [Std error] }\end{array}$ \\
\hline Intercept & & $\begin{array}{l}0.000755 \\
(0.0012)^{* * * *} \\
{[0.000234]}\end{array}$ \\
\hline $\mathrm{TECH}_{\mathrm{t}-1}$ & $\begin{array}{l}0.188977 \\
(0.0000)^{* * * *} \\
{[0.022694]}\end{array}$ & \\
\hline $\operatorname{CDS}_{\mathrm{t}-1}$ & $\begin{array}{l}0.018141 \\
(0.0662)^{*} \\
{[0.009876]}\end{array}$ & \\
\hline
\end{tabular}


Source: Eviews 10 University Version

Notes: *significant at level of $10 \%, * *$ significant at level of $5 \%, * * *$ significant at level of $1 \%$

Notes: MSCI_EU_FIN $t=T E C H_{t-1+} \mathrm{CDS}_{t-1} ; \mathrm{TECH}_{t=\mathrm{C}}$

Table 11

Portmanteau Test using Standard Residual Diagonal BEKK for BANK

\begin{tabular}{cccccc} 
Lags & Q-Stat & Prob. & Adj Q-Stat & Prob. & df \\
\hline \hline 1 & 2.841841 & 0.5846 & 2.844489 & 0.5842 & 4 \\
2 & 9.816734 & 0.2781 & 9.832395 & 0.2770 & 8 \\
3 & 17.64521 & 0.1269 & 17.68280 & 0.1257 & 12 \\
4 & 19.89488 & 0.2250 & 19.94088 & 0.2229 & 16 \\
5 & 24.11002 & 0.2376 & 24.17573 & 0.2348 & 20 \\
6 & 29.04144 & 0.2186 & 29.13486 & 0.2151 & 24 \\
7 & 29.27136 & 0.3989 & 29.36629 & 0.3941 & 28 \\
8 & 33.41052 & 0.3986 & 33.53651 & 0.3927 & 32 \\
9 & 40.30240 & 0.2857 & 40.48663 & 0.2789 & 36 \\
10 & 46.58130 & 0.2199 & 46.82454 & 0.2127 & 40 \\
11 & 48.27149 & 0.3043 & 48.53222 & 0.2953 & 44 \\
12 & 50.38766 & 0.3792 & 50.67231 & 0.3686 & 48 \\
\hline \hline
\end{tabular}

${ }^{1}$ Null hypothesis: No residual autocorrelation up to lag $\mathrm{h}$

${ }^{2}$ Orthogonalization: Cholesky (Lutkepohl)

Table 12

Portmanteau Test using Standard Residual Diagonal BEKK for IBEX

\begin{tabular}{cccccc} 
Lags & Q-Stat & Prob. & Adj Q-Stat & Prob. & df \\
\hline \hline 1 & 4.938825 & 0.2936 & 4.943419 & 0.2932 & 4 \\
2 & 7.094931 & 0.5264 & 7.103540 & 0.5255 & 8 \\
3 & 12.75354 & 0.3872 & 12.77798 & 0.3854 & 12 \\
4 & 14.34874 & 0.5728 & 14.37912 & 0.5705 & 16 \\
5 & 19.96216 & 0.4603 & 20.01875 & 0.4568 & 20 \\
6 & 23.17875 & 0.5093 & 23.25338 & 0.5049 & 24 \\
7 & 23.50290 & 0.7075 & 23.57965 & 0.7035 & 28 \\
8 & 29.08135 & 0.6150 & 29.19988 & 0.6090 & 32 \\
9 & 34.28518 & 0.5503 & 34.44760 & 0.5425 & 36 \\
10 & 36.96452 & 0.6077 & 37.15208 & 0.5992 & 40 \\
11 & 41.61325 & 0.5744 & 41.84883 & 0.5642 & 44 \\
12 & 44.54866 & 0.6151 & 44.81734 & 0.6040 & 48 \\
\hline \hline
\end{tabular}

${ }^{1}$ Null hypothesis: No residual autocorrelation up to lag $\mathrm{h}$

${ }^{2}$ Orthogonalization: Cholesky (Lutkepohl)
Table 13

Portmanteau Test using Standard Residual Diagonal BEKK for MSCI EU FIN

\begin{tabular}{cccccc} 
Lags & Q-Stat & Prob. & Adj Q-Stat & Prob. & df \\
\hline \hline 1 & 7.572840 & 0.1085 & 7.579878 & 0.1082 & 4 \\
2 & 9.241557 & 0.3223 & 9.251700 & 0.3215 & 8 \\
3 & 15.91077 & 0.1954 & 15.93955 & 0.1940 & 12 \\
4 & 19.02444 & 0.2674 & 19.06482 & 0.2653 & 16 \\
5 & 21.99958 & 0.3405 & 22.05384 & 0.3376 & 20 \\
6 & 26.88934 & 0.3096 & 26.97099 & 0.3058 & 24 \\
7 & 28.04596 & 0.4620 & 28.13518 & 0.4573 & 28 \\
8 & 29.67689 & 0.5846 & 29.77831 & 0.5794 & 32 \\
9 & 36.31979 & 0.4538 & 36.47719 & 0.4465 & 36 \\
10 & 37.63378 & 0.5773 & 37.80349 & 0.5696 & 40 \\
11 & 43.07817 & 0.5110 & 43.30406 & 0.5013 & 44 \\
12 & 45.30336 & 0.5840 & 45.55433 & 0.5736 & 48 \\
\hline \hline
\end{tabular}

${ }^{1}$ Null hypothesis: No residual autocorrelation up to lag $\mathrm{h}$

${ }^{2}$ Orthogonalization: Cholesky (Lutkepohl) 